\title{
Relationship between Modified Mercalli Intensity and peak ground acceleration in Myanmar
}

\author{
Santi Pailoplee
}

Earthquake and Tectonic Geology Research Unit (EATGRU), Department of Geology, Faculty of Science, Chulalongkorn University, Bangkok, Thailand; Pailoplee.S@gmail.com

Received 27 June 2012; revised 25 July 2012; accepted 11 August 2012

\begin{abstract}
In this study, the previously reported isoseismal maps are compiled and used to carefully investigate the macroseismic intensity in terms of the Modified Mercalli Intensity (MMI) scale, based on the engineering ground-motion parameter, as the peak ground acceleration (PGA), inferred from the ground-motion attenuation characteristic of Myanmar. The preliminary relationship between the MMI and PGA is reported to be a function of $\log _{10}(P G A)=0.2526 \mathrm{MMI}-3.1006$. The strongly correlated MMI-PGA relationship obtained in this study, if confirmed, will be particularly useful in real-time applications for damage prediction or engineering parameter determination when an earthquake occurs in or nearby to Myanmar. Compared with the previously proposed MMI-PGA relationships for other regions, the standards/provisions of building construction in Myanmar is not high enough to withstand the hazards from earthquakes, particularly at higher levels of ground motion. Therefore, the seismic building code of Myanmar should be modified in order to reduce future hazards arising from earthquakes.
\end{abstract}

Keywords: Isoseismal Map; Modified Mercalli Intensity; Peak Ground Acceleration; Myanmar

\section{INTRODUCTION}

Macroseismic intensity, the descriptive reporting format of earthquake ground shaking, is useful to provide information about the response of structures, quality and type of construction, including the variation of geological conditions in specific areas. However, in practice, a physically based ground-motion measure is needed particularly for engineering purposes. With the advent of current instrumental seismology, the correlation between the felt macroseismic intensity with engineering ground- motion parameters has become a topic of increasing interest. This offers the possibility of transforming readily observed intensity data into widely used engineering ground-motion characteristics and to rapidly assess the severity of ground shaking [1].

With respect to seismic hazards, Myanmar is one of the earthquake-prone areas in Mainland Southeast Asia. Besides the Sumatra-Andaman Subduction Zone in the western part, Myanmar also has own great strike-slip active faults called the "Sagiang Fault Zone" [2]. However, according to the limitation of the political and economic situation, seismic hazard assessment and action is seemingly not recognized within the top priorities in Myanmar. The number of earthquake recording stations is, therefore, low and as a result the earthquake impactions are usually observed in macroseismic intensity and reported manually in terms of isoseismal maps. This method of obtaining data is not enough for the numerical analysis of seismic hazards and in particular is not sufficient for engineering purposes [3].

In this study, it is attempted to develop the relationship between macroseismic intensity, in terms of the MMI scale, and the engineering ground-motion parameter, in terms of the PGA. As such, the main goals of the study are: 1) to gather the macroseismic intensity data that has been previously reported for the Myanmar region and adjacent areas; and 2) to correlate this and contribute the relationship between the felt intensity information and the engineering ground-motion parameter as the PGA.

\section{DATASET}

\subsection{Macroseismic Intensity}

In this study, all macroseismic intensity data are taken from previous publications of isoseismal maps ranked with respect to the MMI scale. Based on careful review, there are 10 isoseismal maps of earthquakes within the magnitude range of a 4.6 - 8.0 Richter scale that have been reported over the past 94 year period (1912-2006 AD) (Figure 1 and Table 1). Most of them were generated from the Sagiang Fault Zone of Myanmar, as mentioned 
1) $23^{\text {rd }}$ May 1912

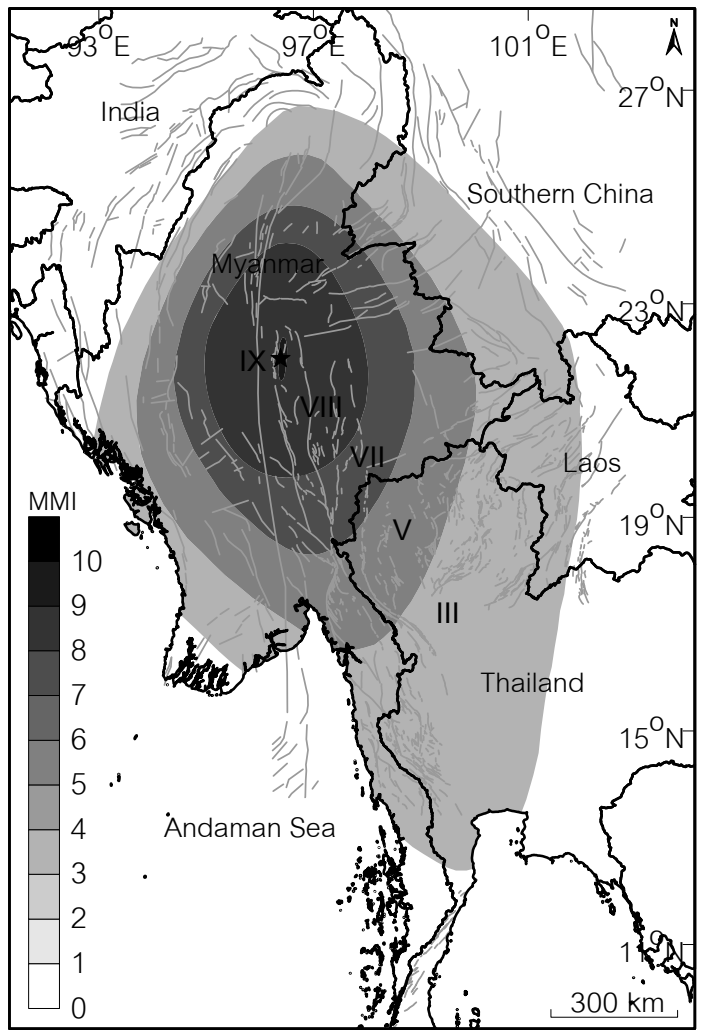

3) $8^{\text {th }}$ August 1929

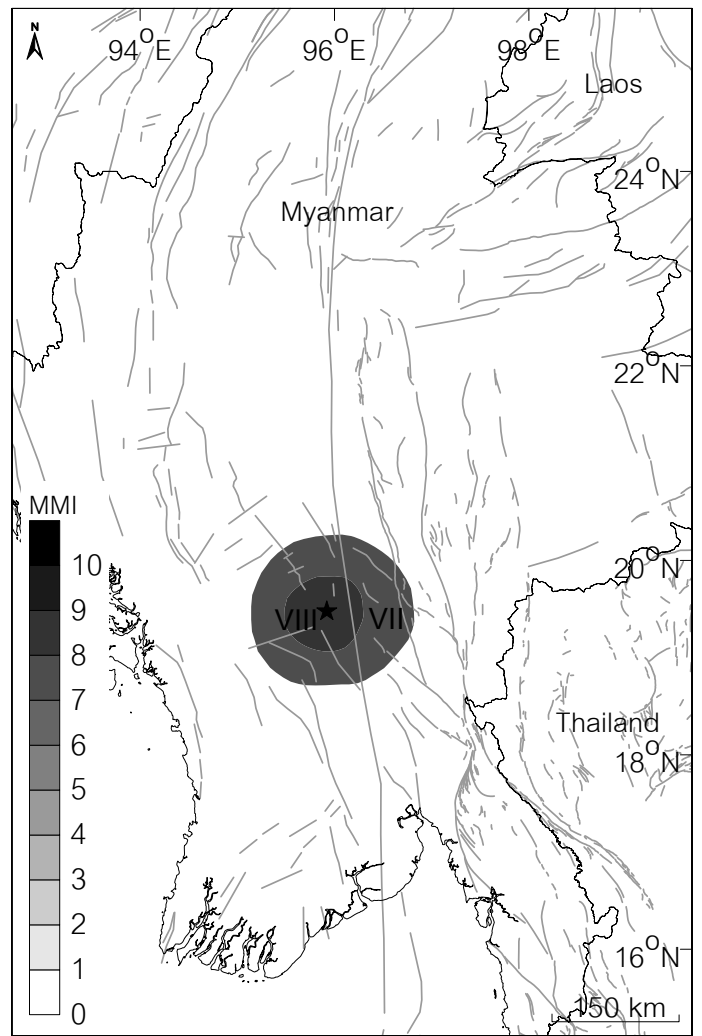

2) $23^{\text {rd }}$ May 1912

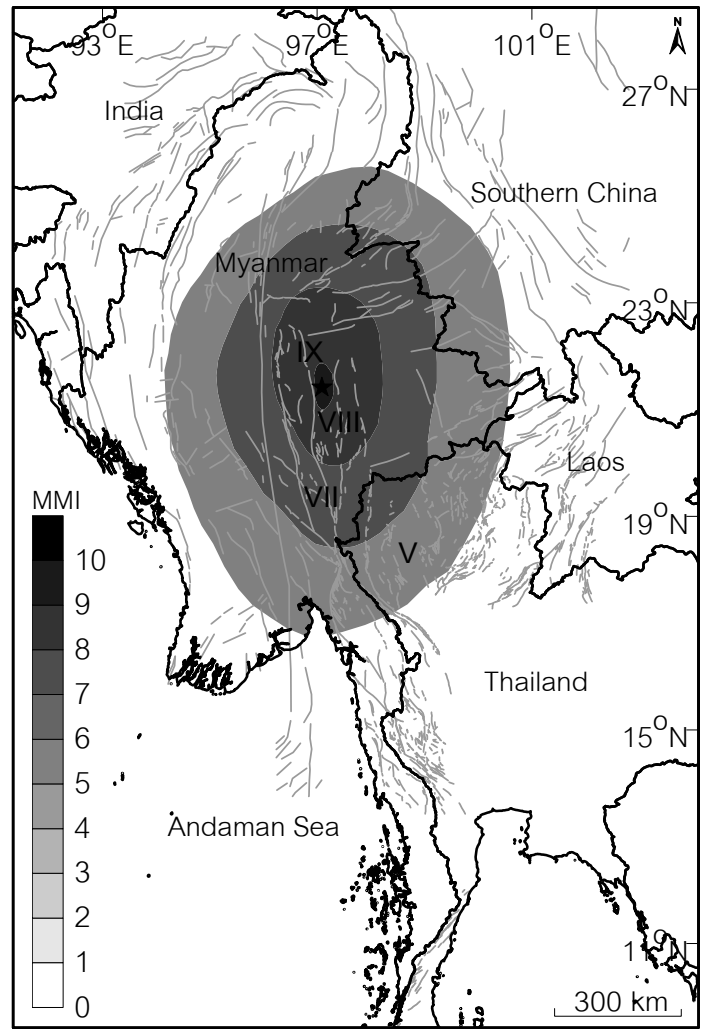

4) $5^{\text {th }}$ May 1930

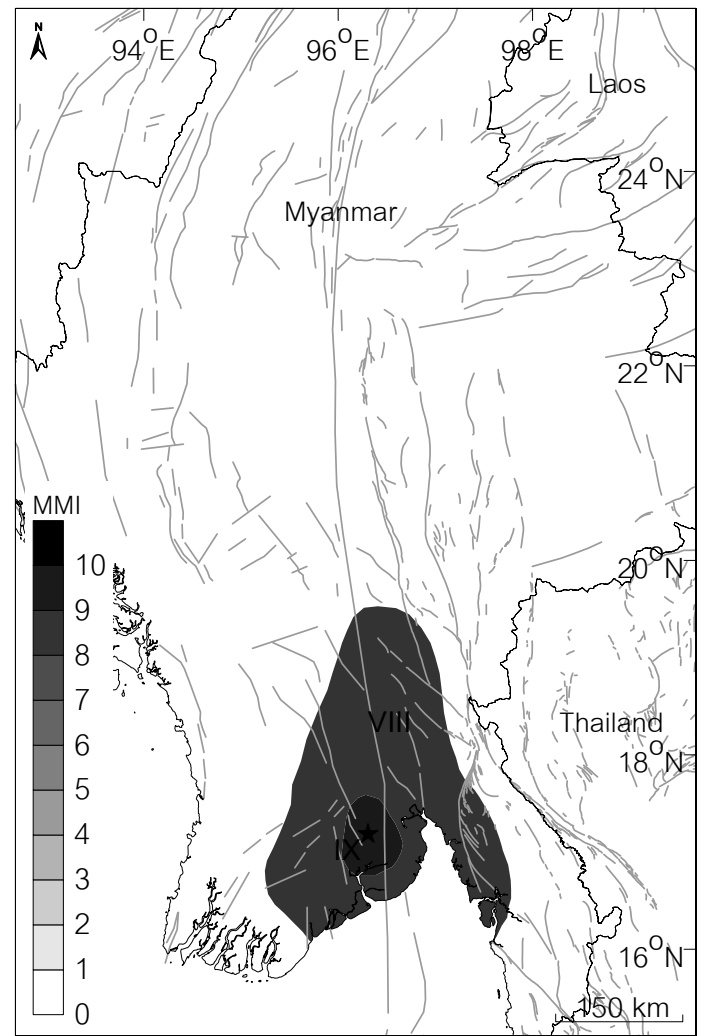


5) $3^{\text {rd }}$ December 1930

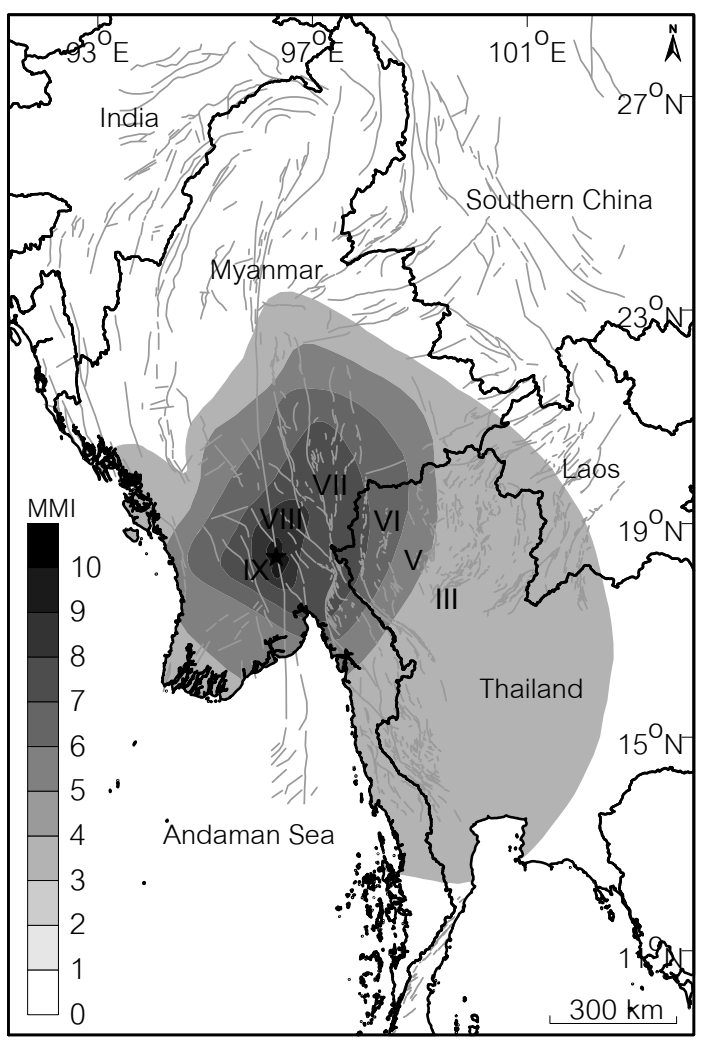

7) $4^{\text {th }}$ December 1930

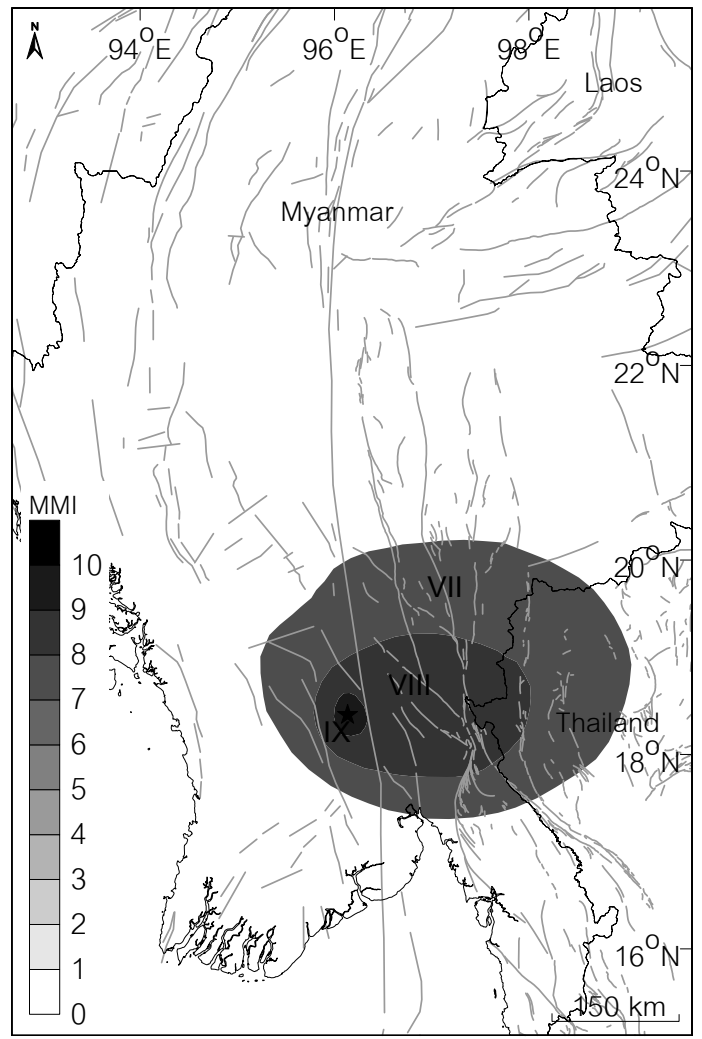

6) $4^{\text {th }}$ December 1930

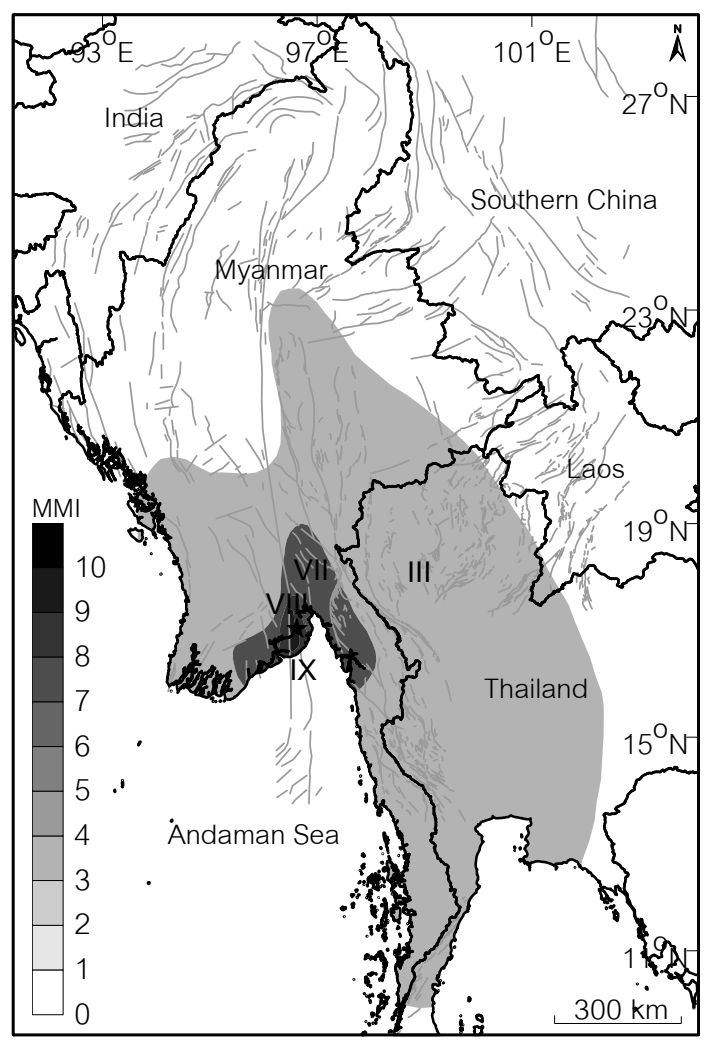

8) $21^{\text {st }}$ March 1954

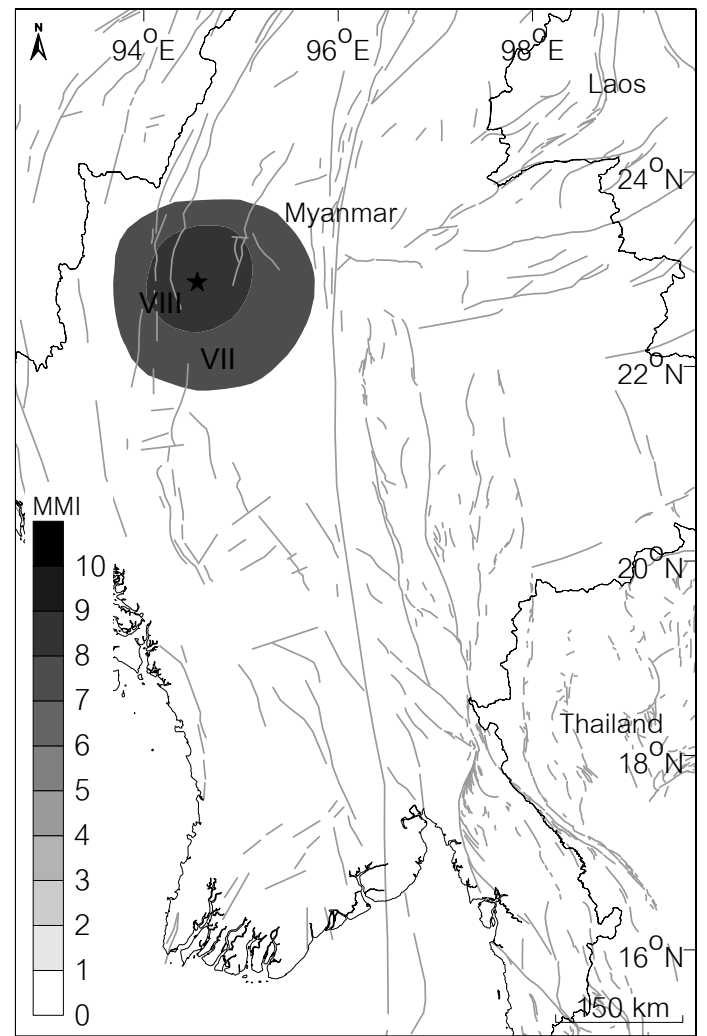


9) $8^{\text {th }}$ October 2006

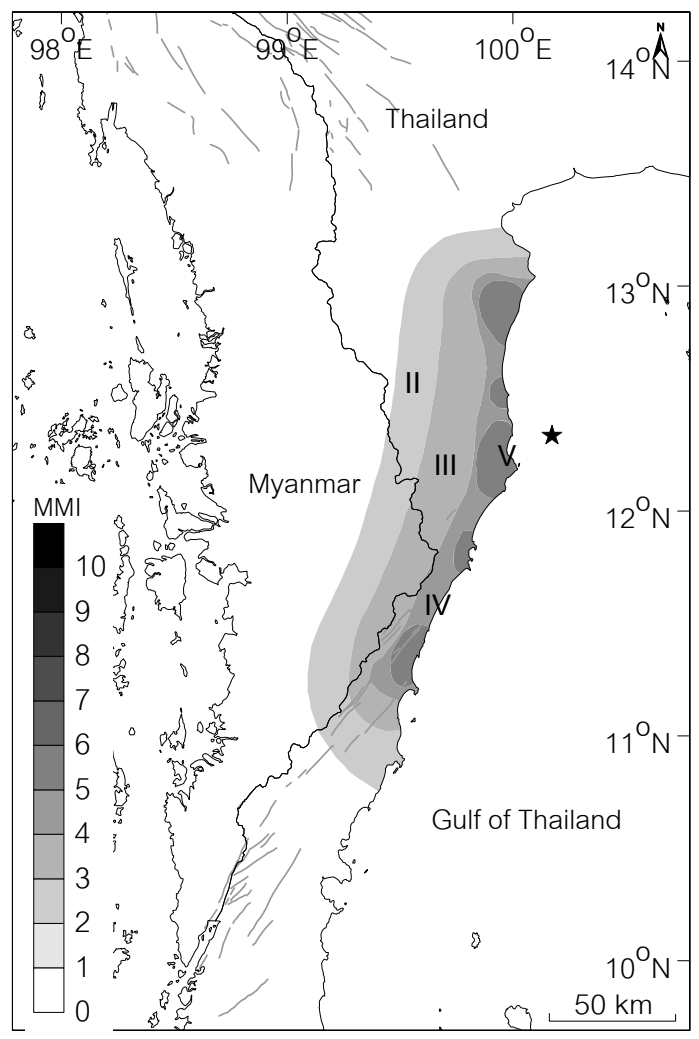

10) $12^{\text {th }}$ December 2006

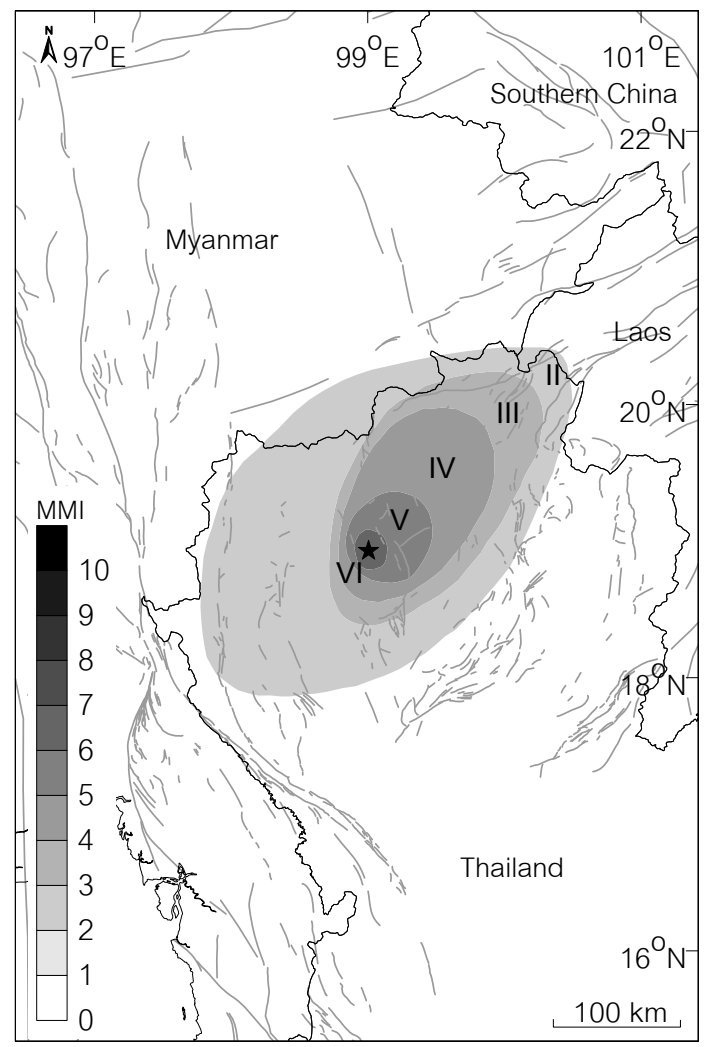

Figure 1. Isoseismal maps of the ten earthquakes reported in Myanmar and neighboring areas during 1912-2006 AD. Grey thin lines illustrate the earthquake faults based on Bender et al. [6] and Pailoplee et al. [4]. Black stars are the locations of past earthquakes whereas the ground shaking intensities are illustrated in terms of gradual color of the MMI scale.

Table 1. List of major earthquake events in Myanmar and adjacent area that had been reported the macroseismic intensity in term of isoseismal maps.

\begin{tabular}{|c|c|c|c|c|c|c|}
\hline No. & Time & Longitude & Latitude & Region & Magnitude (Mw) & Source \\
\hline 1. & 23 ${ }^{\text {rd }}$ May 1912 & 96.43077 & 21.97768 & Mandalay, central Myanmar & 8.0 & [5] \\
\hline 2. & 23 ${ }^{\text {rd }}$ May 1912 & 97.14608 & 21.4492 & Tounggyi, eastern Myanmar & 8.0 & [7] \\
\hline 3. & $8^{\text {th }}$ August 1929 & 95.86302 & 19.48656 & Toungoo, central Myanmar & 7.0 & [7] \\
\hline 4. & $5^{\text {th }}$ May 1930 & 96.58675 & 17.0956 & Pegu, central Myanmar & 7.3 & [7] \\
\hline 5. & $3^{\text {rd }}$ December 1930 & 96.32954 & 18.38407 & Pyu, central Myanmar & 7.3 & {$[8]$} \\
\hline 6. & $4^{\text {th }}$ December 1930 & 96.57656 & 16.84612 & Yangon, central Myanmar & 7.3 & [8] \\
\hline 7. & $4^{\text {th }}$ December 1930 & 96.68823 & 18.85718 & Toungoo, central Myanmar & 7.3 & [7] \\
\hline 8. & 21 $1^{\text {st }}$ March 1954 & 94.52869 & 23.13512 & Mawlaik, western Myanmar & 7.0 & [7] \\
\hline 9. & $8^{\text {th }}$ October 2006 & 100.12143 & 11.80612 & Southern Thailand & 5.0 & [9] \\
\hline 10. & $12^{\text {th }}$ December 2006 & 99.02054 & 18.94165 & Northern Thailand & 4.6 & [10] \\
\hline
\end{tabular}

above, whereas two earthquakes were located in the southern and northern parts of Thailand. These are briefly detailed as follows.

On $23^{\text {rd }}$ May 1912, two earthquakes of a magnitude of
Mw 8.0 devastated Myanmar. The first of these, the Mandalay earthquake, was generated at the central part of the Sagiang Fault Zone and the second, the Tounggyi earthquake, occurred in the Moei-Tounggyi Fault Zone 
[4,5] eastwards of Myanmar. For the Mandalay earthquake, the work of Brown [6] revealed an MMI in the range of III-IX spreading out more than $900 \mathrm{~km}$ from the epicenter to central Thailand (Figure 1). In case of the Tounggyi earthquake, the MMI is in the range of V-IX within the area covering approximately $500 \mathrm{~km}$ from the earthquake location [7].

During 1929-1930 AD, there were five earthquakes within the magnitude of range 7.0 - 7.3 Richter that occurred in the Myanmar region. As a result, five isoseismal maps were contributed and published $[7,8]$. On $8^{\text {th }}$ August 1929, an earthquake with a Mw of 7.0 was generated in Pegu, central Myanmar. Khin and Win [7] reported that the macroseismic intensities were up to a level of VIII in a radius of $150 \mathrm{~km}$ from its source. After that, on $5^{\text {th }}$ May 1930, a Mw-7.3 earthquake occurred again in southern Myanmar, generating a maximum MMI level of IX. Then, on $3^{\text {rd }}-4^{\text {th }}$ December 1930, two earthquakes of approximately the same magnitude $(\sim \mathrm{Mw}$ 7.3) in Pyu and Yangon, respectively, were reported [8]. Both of these were generated by the Sagiang Fault Zone with reported MMIs of up to IX and spread out far away from the source into Thailand (Figure 1). As the same time, on the $4^{\text {th }}$ December 1930, an earthquake with a Mw of 7.3 was also recorded at Toungoo, central Myanmar, with ground shaking intensities in the range of VIIIX. The last isoseismal map in Myanmar gathered in this study is from the Mawlaik earthquake on $21^{\text {st }}$ March 1954, western Myanmar, which had a magnitude of an assumed 7.0 Richter and generated a ground shaking of VII-VIII on the MMI scale.

In addition to the MMI reported in Myanmar, two isoseismal maps obtained from macroseismic intensity investigations in Thailand are added. The first is the Mw5.0 earthquake that occurred on the $8^{\text {th }}$ October 2006 in the southern part of Thailand [9], whilst the second is the Mw 4.6 earthquake located at Chiang Mai province, northern Thailand [10]. Both of these were generated by the Ranong [9] and Mae Tha [11] Fault Zones, which represent the MMI characteristics in the southern and eastern part of Myanmar, respectively. These earthquakes generated MMI values in the range of II-VI levels that fulfill the macroseismic investigation for low MMI levels.

In summary, the data of macroseismic intensity obtained from these 10 collected isoseismal maps have a MMI level in the range of II-IX and so cover almost all of the standard MMI levels (i.e., I-XII), to allow an investigation into the relationship between the MMI and PGA.

\subsection{Engineering Ground-Motion Parameter}

Empirically, the macroseismic intensity is most fre- quently related to the PGA because this engineering ground-motion parameter is the most commonly correlated parameter to structural damage and it is important for seismic resistant structure design [12]. This study, therefore, used the PGA to calibrate with the obtained macroseismic intensity data.

However, according to the limitations of the available PGA data in Myanmar, in particular for the past 100 years of earthquake events that are reported only as isoseismal maps, then here the PGA is assumed for this calibration. To this end, based on the published probabilistic seismic hazard map of the Yangon area, central Myanmar ([13], the maps were evaluated by using the strong ground-motion attenuation relationship of Boore et al. [14]. Thus, in this study, the PGA values used for calibration with the MMI are inferred using the groundmotion attenuation characteristic of Boore et al. [14], as shown in Equation (1).

$$
\begin{aligned}
\ln Y= & b_{1}+b_{2}(M-6)+b_{3}(M-6)^{2}+b_{4} R \\
& +b_{5} \log (R)+b_{6} G_{B}+b_{7} G_{C}
\end{aligned}
$$

where $Y$ is the PGA which is in $\mathrm{g}$ unit $\left(1 \mathrm{~g}=981 \mathrm{~cm} / \mathrm{s}^{2}\right)$, $M$ is the moment magnitude ( $\mathrm{Mw}), R$ is the source-to-site distance $(\mathrm{km})$, for randomly-oriented horizontal component (or geometrical mean) $b_{1}=0.105, b_{2}=0.229, b_{3}=0$, $b_{4}=0, b_{5}=-0.778, b_{6}=0.162, b_{7}=0.251, G_{B}=1$, and $G_{C}=0$.

From the isoseismal maps described above, the individual area of each MMI level was gridded with a spacing of $1 \times 1 \mathrm{~km}$ to measure the source-to-site-distances that the seismic wave traveled and was attenuated over. Practically for each MMI level, there is more than one value or the source-to-site-distances (i.e., the MMI boundary is not a perfect circle), and consequently the average distance was used. The magnitudes required in equation (1) and the earthquake locations for measuring the source-to-site-distances are those cited in previous reports and are detailed in Table 1.

\section{MMI-PGA RELATIONSHIP}

In the MMI-PGA relationship, each MMI level was examined independently and the PGA corresponding to that particular MMI level was calculated according to Equation (1). After that, each MMI value was plotted against the corresponding calculated PGA, as shown in Figure 2. The different symbols used in Figure 2 distinguish the MMI-PGA data obtained from individual isoseismal maps.

From Figure 2, it is revealed that the series of MMIPGA calibration vary in individual MMI range. Thus, all values of PGA in each MMI are averaged statistically. Thereafter, the obtained mean PGA is plotted against the MMI. In final, the MMI-PGA relationship is contributed 
using the linear regression.

From the result of this regression (Figure 2), it appears that there is a slight trend of MMI to be a linear function in relationship to the $\log _{10}$ (PGA), which can represented by Equation (2) with a standard deviation of 0.33 .

$$
\log _{10}(\mathrm{PGA})=0.2526 \mathrm{MMI}-3.1006
$$

where PGA is the peak ground acceleration $\left(\mathrm{cm} / \mathrm{s}^{2}\right)$ and MMI is the level of macroseismic intensity in terms of MMI scale.

\section{DISCUSSION AND CONCLUSION}

A new relationship between macroseismic intensity and engineering ground-motion parameter is contributed for the Myanmar region by comparing the MMI gathered from 10 isoseismal maps with the inferred PGA. Based on the resultant MMI-PGA calibration, the obtained relationship appears as a function of $\log _{10}(\mathrm{PGA})=0.2526 \mathrm{MMI}-3.1006$. This relationship, if substantiated, will be particularly useful in real-time applications for damage prediction or engineering parameter determination for earthquake ground shaking posed in or nearby to Myanmar.

Focusing to the other region, many empirical equations have been proposed to relate the MMI with PGA (Figure 3). In comparison with these, the MMI-PGA relationship for Myanmar reported here illustrates that in the same engineering ground-motion level, that is the same PGA level, the MMI of Myanmar is reported at a lower level than those for the other region until level $\mathrm{V}$

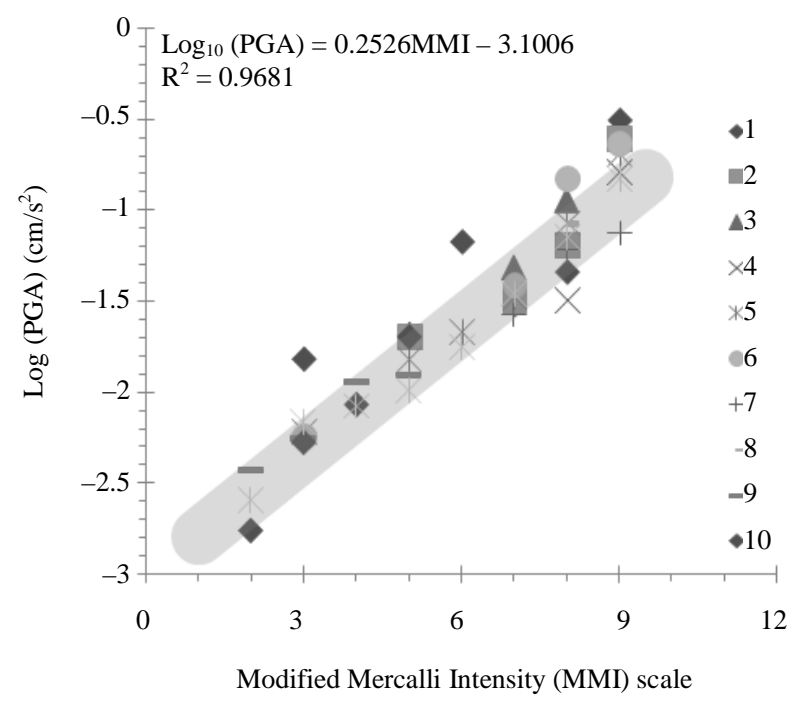

Figure 2. Relationship between the PGA $\left(\mathrm{cm} / \mathrm{s}^{2}\right)$ and the MMI scale. The series of MMI-PGA data are distinguished by different symbols and the numbers correspond to the isoseismal maps in Figure 1. The correlation coefficient $\left(\mathrm{R}^{2}\right)$ for the shown linear regression is 0.9681 .

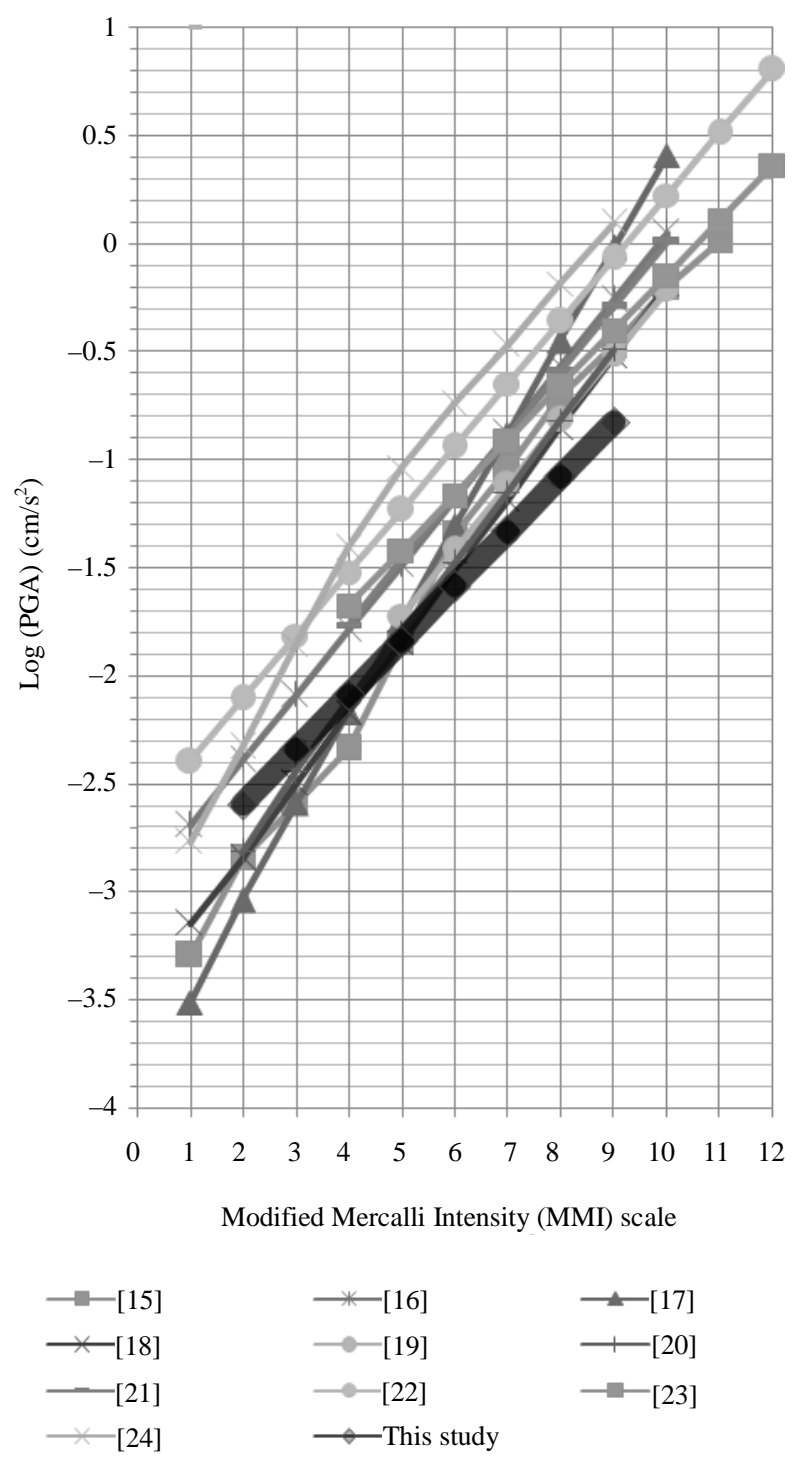

Figure 3. Comparison of MMI-PGA relationship determined from this study (thick black line) and the others proposed previously for different regions.

of the MMI scale (i.e., felt by nearly everyone; many awakened. Some dishes, windows broken. Unstable objects overturned. Pendulum clocks may stop). However, for MMI values of equal to or larger than level VI, which mainly represent the destruction of infrastructures or buildings, the same PGA generates a higher MMI level than the other regions. This implies that the standard of building construction in Myanmar, in terms of withstanding earthquake hazards, is not high enough such that low ground motions contribute to a high degree of structure damage, particularly at higher levels of ground shaking. Thus, for the reduction of earthquake hazards in Myanmar, earthquake hazard situations should be realized and the standard building code should be modified accordingly to withstand such ground movement. 
However, it is recognized that there is a significant level of uncertainty in estimating ground motions (i.e., PGA) from the existing isoseismal maps by this process. Therefore, further work is required to check these PGA values carefully for consistency with those of the instrumentally recorded data. The uncertainties in the variables used in the damage estimation should also be discussed.

\section{ACKNOWLEDGEMENTS}

Financial support is acknowledged from the Faculty of Science, Chulalongkorn University through the Thai Government Stimulus Package 2 (TKK2555: PERFECTA); The National Research University Project of CHE; and the Ratchadaphiseksomphot Endowment Fund (Project Code CC508B). Thanks also extend to T. Pailoplee for the preparation of the draft manuscript. We thank the Publication Counseling Unit (PCU), the Faculty of Science, Chulalongkorn University for a critical review and improved English. We acknowledged thoughtful comments and suggestions by the Editor-In-Chief and anonymous reviewers which enhanced the quality of this manuscript significantly.

\section{REFERENCES}

[1] Wald, D.J., Quintoriano, V., Heaton, T.H., Kanamori, H., Scrivner, C.W. and Worden, C.B. (1999) TriNet "Shakemaps": Rapid generation of peak ground motion and intensity maps for earthquakes in southern California. Earthquake Spectra, 15, 537-555. doi:10.1193/1.1586057

[2] Le Dain, A.Y., Tapponnier, P. and Molnar, P. (1984) Active faulting and tectonics of Burma and surrounding regions. Journal of Geophysical Research, 89, 453-472. doi:10.1029/JB089iB01p00453

[3] Kramer, S.L. (1996) Geotechnical earthquake engineering. Prentice Hall, Inc., Upper Saddle River, 653.

[4] Pailoplee, S., Sugiyama, Y. and Charusiri, P. (2009) Deterministic and probabilistic seismic hazard analyses in Thailand and adjacent areas using active fault data. Earth, Planets and Space, 61, 1313-1325.

[5] Bender, F. (1983) Geology of Burma. Gebrüder Bornträger, Berlin.

[6] Brown, J.C. (1914) The Burma earthquake of May 1912. Memoirs of the Geological Survey of India, 13, 1-147.

[7] Khin, A. and Win, K. (1968) Preliminary studies of the paleogeography of Burma during the Cenozoic. Union of Burma Journal of Science and Technology, 1, 241-251.

[8] Brown, J.C. and Leicester, P. (1933) The Pyu earthquake of 3rd and 4th December, 1930 and subsequent Burma earthquakes up to January 1932. Memoirs of the Geological Survey of India, 42, 1-140.

[9] Thipyopass, S. (2010) Paleoearthquake investigation along the Ranong Fault Zone, southern Thailand. M.Sc. Thesis, Chulalongkorn University, Bangkok.

[10] Department of Mineral Resources (2006) Macroseismic investigation in Chiang Mai Province, Northern Thailand. Department of Mineral Resources, Bangkok.

[11] Rhodes, B.P., Perez, R., Lamjuan, A. and Kosuwan, S. (2004) Kinematics and tectonic implications of the Mae Kuang Fault, northern Thailand. Journal of Asian Earth Sciences, 24, 79-89. doi:10.1016/j.jseaes.2003.09.008

[12] Krinitzsky, E.L. and Chang, F.K. (1988) Intensity-related earthquake ground motion. Bulletin of the International Association of Engineering Geology, 4, 425-435.

[13] Htwe, Y.M.M. and Wenbin, S. (2010) Seismic hazard maps of Yangon and its surrounding areas. Geo-Spatial Information Science, 13, 230-234.

[14] Boore, D.M., Joyner, W.B. and Fumal, T.E. (1997) Equations for estimating horizontal response spectra and peak acceleration from western North American earthquakes: A summary of recent work. Seismological Research Letters, 68, 128-153. doi:10.1785/gssrl.68.1.128

[15] Kawasumi, H. (1951) Measures of earthquake danger and expectancy of maximum intensity throughout Japan as inferred from the seismic activity in historical times. Bulletin of the Earthquake Research Institute, Tokyo University, Tokyo, 469-482.

[16] Neumann, F. (1954) Earthquake intensity and related ground motion. WSU Press, Seattle.

[17] Hershberger, J. (1956) A comparison of earthquake accelerations with intensity ratings. Bulletin of the Seismological Society of America, 46, 317-320.

[18] Richter, C.F. (1958) Elementary seismology. W.H. Freeman, San Francisco, 768.

[19] Medvedev, S.V. and Sponheuer, W. (1969) Scale of seismic intensity. Proceedings of the 5th World Conference Earthquake Engineering, Santiago, 13-18 January 1969. 135-138.

[20] Okamoto, S. (1973) Introduction to earthquake engineering. John Wiley, New York.

[21] Trifunac, M.D. and Brady, A.G. (1975) On the correlation of seismic intensity scales with the peaks of recorded strong ground motion. Bulletin of the Seismological Society of America, 65, 139-162.

[22] Theodulides, N.P. and Papazachos, B.C. (1992) Dependence of strong ground motion on magnitude-distance, site geology and macroseismic intensity for shallow earthquakes in Greece: I, peak horizontal acceleration, velocity and displacement. Soil Dynamics and Earthquake Engineering, 11, 387-402. doi:10.1016/0267-7261(92)90003-V

[23] Shabestari, K.T. and Yamazaki, F. (2001) A proposal of instrumental seismic intensity scale compatible with MMI evaluated from three-component acceleration records. Earthquake, 17, 711-723. doi:10.1193/1.1425814

[24] Kaka, S. and Atkinson, G. (2004) Relationships between instrumental intensity and ground motion parameters in eastern North America. Bulletin of the Seismological Society of America, 94, 1728-1736. doi:10.1785/012003228 